\title{
Segmenting the Performing Arts Markets: The Case of Czech National Theater Attenders' Motivations
}

\author{
Chytková Zuzana, Cerná Jitka, Karliček Miroslav
}

\begin{abstract}
Strategic marketing instruments such as segmentation and targeting can benefit performing arts institutions and render their offer more competitive. To segment classical performing arts audiences, however, the traditionally used variable is social class. In this paper, it is argued that such often suggested traditional segmentation criteria can prove to be context-insensitive and as such cannot be applied invariably across different settings. Based on an analysis of Czech National Theater audiences and its motivations, we propose the sought benefit of the theater visit as an alternative segmentation basis that may prove to be more context-sensitive.
\end{abstract}

Key words: marketing, performing arts, National Theater, consumer behavior

\section{INTRODUCTION: MARKETING AND PERFORMING ARTS}

It is now a fairly widely accepted fact that the concept of marketing applies to all organizations with products and customers, not only to those strictly business oriented (Kotler \& Levy, 1969; Andreasen, 2012). Yet, from an applicative point of view, it has been noted that marketing of (performing) arts is different in its application than the traditional commercial marketing (Fraser, 2004). Often, it tends to be tactical in nature, concentrating on selling the performance, rather than designing the product based on consumers' needs (Fraser, 2004; Pallin, 2003). The design of the product, then, becomes a rather intuitive exercise. This is clearly at odds with the traditional marketing concept that is based on the individuation of consumer needs and their subsequent satisfaction with the right marketing mix (e.g. Kotler \& Armstrong, 2007).

This situation may reflect considerations voiced by some scholars (Becker, 1978; Hirschman, 1983; Harrison, 2009) who argued that this traditional marketing process that takes its departure from the individuation of consumer needs, is not applicable in case of high artistic production, since artists are defined as those who create freely without primarily considering the needs they will satisfy. This view is based on the presumption that there is a division between high and low cultural production, where high culture is seen as art pursued for its own sake, while popular or low culture is defined as the kind of artistic production that primarily targets consumers (e.g. Holbrook, 1995). Marketing, thus, would be wholly applicable in the sphere of popular (low) art, but not in the area of high cultural production (including performing arts such as theater, ballet, opera). The practical result of such division, then, is the sole application of marketing techniques of tactical nature (mostly communication) in the area of high arts, leaving aside its strategic instruments, including segmentation and targeting of consumers, and positioning of the product. Such view, however, has become increasingly problematic, not least because the distinction itself between high and low artistic production has been fading and has started to disappear (Featherstone, 1991; Venkatesh \& Meamber, 2006). In postmodern consumer culture, in fact, 
the marketplace becomes the means and locus of the very culture's reproduction (Arnould \& Thompson, 2005), while marketing plays a central role in this process, be it for high or popular cultural production. Hence, it becomes increasingly non-sensical even in the area of high cultural production to apply the outdated "product-oriented" approach to marketing that focuses on selling whatever product is "in stock", rather than creating an offer based on consumers' needs (Botti, 2000).

As a consequence, there is now little doubt that even classical performing arts organizations can benefit from sensibly applied strategic marketing tools that allow them to individuate consumer needs and design the market offer accordingly. In particular, what is seen as the most fundamental aspect of performing arts marketing is segmentation and targeting (e.g. Kotler \& Scheff, 1997; Bernstein, 2007). The literature offers guidelines on how to segment performing arts markets, yet most of it does not consider the contextual sensitivity of the segmentation criteria. These, then, can, but do not necessarily apply in different contexts. This is so also due to the fact that most research is carried out on a national basis, while there is a lack of international comparisons (Falk \& Falk, 2011). While it is not the purpose of this paper to pursue such goal, it nonetheless seeks to verify if the generally accepted criteria used to segment performing arts markets do apply in the Czech national context and to find alternatives that could prove to be more context sensitive.

\section{SEGMENTING CLASSICAL PERFORMING ARTS AUDIENCES}

Segmentation of performing arts audiences, as one of the most fundamental techniques of targeted marketing, has been widely discussed in literature (e.g. Kotler \& Scheff, 1997; Berstein, 2007). The relevant literature then concentrates mostly on describing the markets (audiences) in terms of variables applicable to segmentation. Some of the literature considers variables such as age or geographical factors (Kotler \& Scheff, 1997; Ngobo, 2005; Favaro \& Frateschi, 2007; Ateca-Amestoy; 2008; Willis, Snowball, Wymer, and Grisolía, 2012). Kotler \& Scheff (1997) in their book on marketing of performing arts suggest both as the possible criteria for segmenting the performing arts markets. Such suggestion is supported by numerous studies on regard. For example Ngobo (2005) finds that age is a significant moderator in consumers' frequency of performing arts attendance. Similarly, Favaro \& Frateschi (2007) in their study of Italian audiences, although in this case the effect is moderated by type of performance attended. Similarly, Ateca-Amestoy reported on increasing frequency of performance attendance with increasing age attributing this to the necessary accumulation of cultural capital. Willis et al. (2012), on the other hand, show that geographical distance negatively influences the number of theater visits.

Most research on regard, however, centers around one or more components of social class, such as income, education or occupation (Solomon et al., 2010), which also compose variables most often suggested for performing arts audience segmentation (Kotler \& Scheff, 1997). Within the classic literature in the field, DiMaggio, Useem \& Brown (1978), for instance, report on underrepresentation of minorities at classical performances and presume this effect to be due to their lower income and lower achieved education. Andreasen (1987) shows that more frequent attenders of classical performances tend to be of higher education or higher income, and that these consumers have been socialized to performing arts in childhood (Andreasen, 1987). The 
assertion about the role played by early socialization has been corroborated by Andreasen and Belk (1980), who have shown early childhood exposure to performing arts is a predictor for adult performance attendance. This conclusion resonates with the classic Bourdieu's (1984) study, that described cultural capital (needed to consume high cultural production) partly acquired through socialization as one of the key components of social class.

More recent research then confirms the former findings. Lewis \& Seaman (2004) show that higher education among homosexuals means higher attendance levels. Borgonovi (2004) shows that higher overall education and higher income leads to a more complete art education of consumers which then increases the performing arts attendance frequency. Similarly, Maters, Russell, and Brooks (2001) show education to be significant in predicting Australians' performing arts attendance. And in an international comparison of EU countries, then, Falk \& Falk (2011) find all the traditional components of social class, e.g. income, education and occupation to be significant in predicting consumers' performing arts attendance.

As a result of these findings, the segments targeted by performing arts institutions are often defined in terms of social class. This practice is accused of leading to the exclusion of "the masses" as those who do not possess the qualification to appreciate the product (Huntington, 2007). Marketing techniques and particularly segmentation have thus been accused of having discriminatory effects, as they limit access to these products to those deemed an inappropriate segment (Hollander, 1984; Huntington, 2007).

Although these considerations are of utmost importance, we argue that most of the previous studies have concentrated on a specific market and their results thus do not necessarily apply uniformly across different contexts. We want to show that in the particular case of the Czech National Theater, the traditional social class approach to defining the audience is inappropriate, as the audience is not homogeneous from this point of view. As a consequence, we argue that in the application of marketing theory and practice, what should be considered carefully are not only the specificities of performing arts institutions and recent societal developments, but also the specific context of a particular institution. We further suggest that an approach considering visitors' motivations for attending the performance may represent a better and more contextsensitive segmentation basis.

\section{CONTEXT AND METHODOLOGY}

In order to check for the contextual validity of the segmentation criteria traditionally offered for segmenting performing arts audiences, and to look for new, more context-sensitive options, we have chosen the setting of the Czech National Theater. We have used its customers to show that the traditional variables used to describe and segment performing arts audiences do not necessarily apply in all settings. Within the realm of performing arts, the Czech National Theater is the number one Czech aesthetic producer of the high culture. Its products, the performances, are not designed according to the consumers' needs, as the traditional marketing concept would have it, and are therefore ideologically neutral in the sense proposed by Hirschman (1983).

Our research is based on a quantitative study carried out throughout 2011. The study consisted in a questionnaire that was administered to National Theater customers. The questionnaire contained questions about the frequency of consumers' attendance to National Theater perform- 
ances to understand if the consumer was a regular, occasional or first-time attender, questions about the type of performance attended (as the National Theater offers drama, opera and ballet) and an open question that sought to uncover the motivation for attendance. This question was open, in order to explore consumers' own perceptions and understand the benefits perceived by consumers in their own terms. The questionnaire then contained questions about sociodemographic descriptors, such as gender, age, education level, income or place of residence.

The sample consisted of 1279 respondents. As can be seen at Fig. 1, the sample was well balanced in terms of age.

\section{Respondents' age}

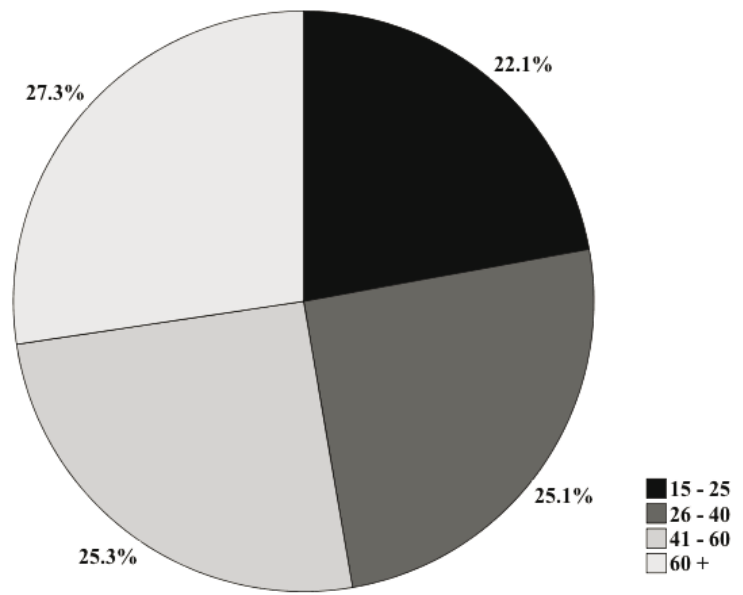

Fig. 1 - Age composition of the sample. Source: Authors

The sample contained $68 \%$ of women and $32 \%$ of men. More than half $(58 \%)$ of the respondents were university educated, followed in number by the group of high-school educated consumers. The overrepresentation of women, as well as university educated respondents may be due to the particular composition of the National Theater attendees, where precisely these groups of consumers are the more frequent theater goers. Finally, as illustrated at Fig. 2, a great proportion of respondents had household income level bellow 30 thousand CZK (36\%), 14\% between 30 and 40 thousand, $9 \%$ between 40 and 50 thousand, while the rest had a higher income. 


\section{Household income}

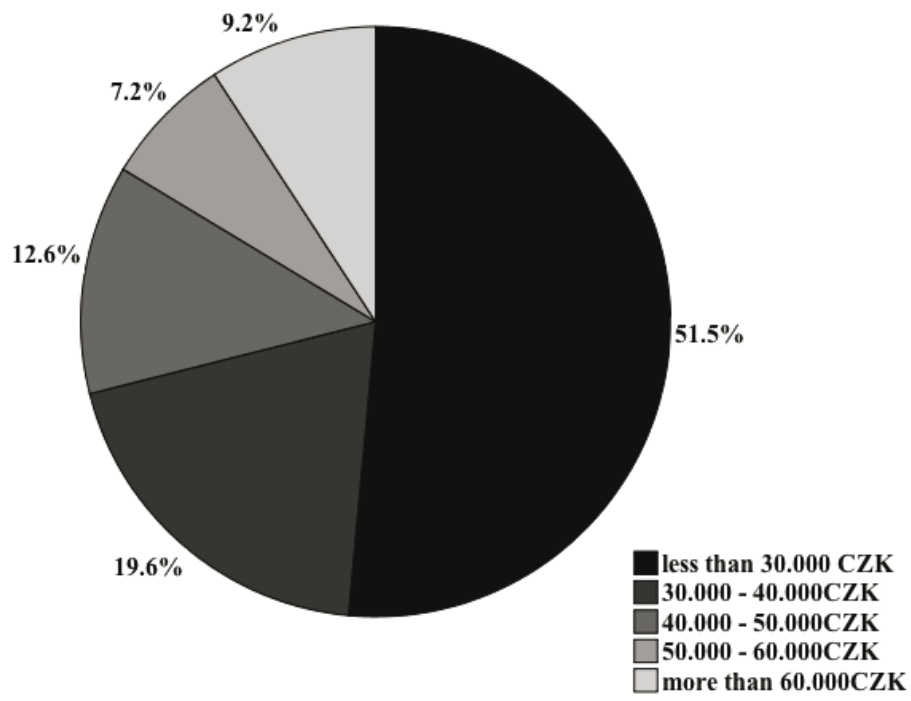

Fig. 2 - Composition of the sample: Housebold income. Source: Authors

Because all of the variables included in the questionnaire were categorical, we have used the chi-square test of independence and adjusted standardized residuals to illustrate the relations between the frequency of National Theater attendance and variables used in literature to describe classical performing arts audiences, as well as the variable "motivation for visit". In particular, we first used Chi-Square test to test the independency of the various variables and the variable "Frequency of visit". Then, we used adjusted standardized residuals to see which categories combinations are over or underrepresented. By convention, if the adjusted standardized residual is more than 2 , the cell presents significantly more cases than expected, while if less than -2 , it presents significantly less cases than expected (Agresti, 2002). This then helps with the interpretation of the Chi-Square results.

In this way, it is possible to assert if the traditional variables described in literature used to describe and segment the performing arts market do apply in this particular case, and possibly to uncover other variables that play a role in the theater attendance and that can thus be used in the application of marketing.

\section{FINDINGS}

\subsection{Traditional view of performing arts audiences: key variables revisited}

As mentioned above, previous research has shown in particular the structuring effect of age and geographical factors (Holbrook \& Schindler, 1994; Kotler \& Scheff, 1997, Ngobo, 2005; Favaro \& Frateschi, 2007; Ateca-Amestoy; 2008; Willis et al.,2012), or social class (DiMaggio \& Useen, 1978 ) or some of its components such as income, education or occupation (Baumol \& Bowen, 
1966; Andreasen \& Belk, 1980; Kotler \& Scheff, 1997; Lewis \& Seaman, 2004; Borgonovi, 2004; Masters et al., 2011; Falk \& Falk, 2011). We start our analysis by reviewing if such variables do present a relation to consumers' National Theater attendance frequency and if, thus, it is possible to assert that they can be used to predict if a person is a frequent theater attender.

Tab. 1 - Age/frequency of performance attendance. Source: Authors

\begin{tabular}{|c|c|c|c|c|}
\hline & $\mathbf{1 5 - 2 5}$ & $\mathbf{2 6 - 4 0}$ & $\mathbf{4 1 - 6 0}$ & $\mathbf{6 0 +}$ \\
\hline More than once a year & -4.9 & -0.9 & -0.5 & 6 \\
\hline Once a year & 1.8 & 1.3 & 1 & -4 \\
\hline First visit & 7 & -0.8 & -1.1 & -4.7 \\
\hline
\end{tabular}

Similarly to some previous studies (e.g. Ngobo, 2005; Favaro \& Frateschi, 2007; Ateca-Amestoy; 2008), what was found significant for the frequency of attendance was age (Chi-square $=79.265$, significant at $1 \%$ significance level). What can be noted in particular in the Tab. 1 are the significant (more than 2 or less than -2 , evidenced in grey) adjusted standardized residuals that offer an illustration of which age groups tend to be over or underrepresented for each visit frequency group. What stands out here is the overrepresentation of older consumers (over 60) in the frequent theater goers group who attend the theater more times during the year. Quite understandably, then, young consumers are often first-timers and much less often regulars. Interestingly, this is at odds with what found by Falk \& Falk (2011) who found a decreasing tendency in attendance with increasing age.

Tab. 2 - Place of residence/frequency of performance attendance. Source: Authors

\begin{tabular}{|c|c|c|c|c|c|}
\hline & Prague & $\begin{array}{c}\text { Central Bo- } \\
\text { hemia more } \\
\text { than 20 } \\
\text { thousand }\end{array}$ & $\begin{array}{c}\text { Central } \\
\text { Bohemia } \\
\text { less than 20 } \\
\text { thousand }\end{array}$ & $\begin{array}{c}\text { Other } \\
\text { region more } \\
\text { than 20 } \\
\text { thousand }\end{array}$ & $\begin{array}{c}\text { Other } \\
\text { region less } \\
\text { than 20 } \\
\text { thousand }\end{array}$ \\
\hline $\begin{array}{c}\text { More than } \\
\text { once a year }\end{array}$ & 6.6 & -1.6 & -1.7 & -4.4 & -4.0 \\
\hline Once a year & -4.1 & 1.9 & 1.6 & 0.9 & 3.2 \\
\hline First visit & -6.0 & -0.4 & 0.3 & 7.9 & 2.2 \\
\hline
\end{tabular}

What was also found significant to the frequency of the National theater attendance, also in line with previous studies (Kotler \& Scheff, 1997, Huntington, 2007; Willis et al., 2012), were geographical factors, namely the consumers' place of residence (Chi-Square $=99.232$, significant at $1 \%$ significance level). As can be seen in Tab. 2, not surprisingly, Prague residents are among the most frequent visitors, while their count is underrepresented in groups that visit the theater once a year or less. Also not surprisingly, consumers residing in further distance from the capital tend not to be among the frequent attendees. Interestingly, however, consumers coming from further distance, but from towns that count less than 20000 inhabitants, are overrepresented among those, who visit the theater once a year. This effect could be caused for instance by the unavailability of cultural program in their own place of residence. 
Tab. 3 - Education/frequency of performance attendance. Source: Authors

\begin{tabular}{|c|c|c|c|}
\hline & Compulsory & High school & University \\
\hline More than once a year & -1.3 & -5.1 & 5.5 \\
\hline Once a year & -0.4 & 4.8 & -4.5 \\
\hline First visit & 3.8 & 1.3 & -2.6 \\
\hline
\end{tabular}

Last, in line with other studies (e.g. Baumol \& Bowen, 1966; Lewis \& Seaman, 2004; Masters et al., 2011), we have found a significant influence of education (Chi-Square $=43.061$ at $1 \%$ significance level), where especially the group of regular attenders showed an overrepresentation of university educated consumers, and underrepresentation of consumers with lower education (see Tab. 3). Such result may appear as corroborating previous studies that pointed out social class as the main descriptor of theater attenders. Yet, our data show that such effect is rather problematic.

In contrast to formerly published studies (e.g. Borgonovi, 2004), in fact, we have found no significant effect of income (Chi-Square $=6.715)$, as can also be seen from Tab. 4 that shows no adjusted standardized residual is above 2 or below -2 .

Tab. 4 - Household income (in thousands CZK)/frequency of performance attendance. Source: Authors

\begin{tabular}{|c|c|c|c|c|c|}
\hline & $\begin{array}{c}\text { Less than } \\
\mathbf{3 0}\end{array}$ & $\mathbf{3 0 - 4 0}$ & $\mathbf{4 1 - 5 0}$ & $\mathbf{5 1 - 6 0}$ & $\begin{array}{c}\text { more than } \\
\mathbf{6 0}\end{array}$ \\
\hline More than once a year & -0.1 & -1.1 & 1.1 & -0.4 & 0.8 \\
\hline Once a year & 0.4 & 1.3 & -1.7 & -0.2 & -0.5 \\
\hline First visit & -0.8 & -0.3 & 1.1 & 1.1 & -0.6 \\
\hline
\end{tabular}

Because income is one of the key components of social class (Solomon et al., 2010), this result problematizes the role of social class in the segmentation of performing arts audiences. As noted above, it has been argued that social class is a key explanative variable for performing arts market segmentation (Huntington, 2007) and previous studies have generously shown the association of income and educational level on the attendance of performing arts.

Yet, it can be argued that social class is a contextually dependent variable that in different contexts may play out in heterogeneous ways. In the particular context of Czech republic, which is in the process of transformation from communism, income does not play a role in people's attendance of the National Theater, as for decades art was "marketed" to the wide population. In this respect, we partially corroborate Huntington's (2007) claim about the discriminatory effect of segmentation practices of the performing arts market, as we can demonstrate that in a context where no such practices were in place (indeed, were precluded by the same state), income does not play a role in people's attendance.

The traditional models of performing arts audience segmentation that are based on the presumption that the performing arts consumers, especially theater goers, belong to the high-income group can thus be said to be insensible to the particular context and as such cannot be applied uniformly and unreflexivelly across different settings. 


\subsection{What consumers want from their theater?}

For the reasons stated above we propose to pursue and deepen another perspective on performing arts customers and their possible segmentation that we found significant: that of benefits that consumers seek when attending the theater. Several authors have treated the topic, e.g. Botti (2000), who described different kinds of benefits sought from the cultural experience, such as functional, symbolic, social or emotional.

In order to uncover what benefits consumers sought, we first coded the answers to the open question that sought to uncover the motivation for attendance. The resulting groups were the following: repertoire, culture, tradition, atmosphere, children, fun, interest in theater, casting, quality, opera, ballet, building/environment, and prestige. Their respective percentual representation is to be seen in Fig. 3. It should be noted that because the treated subject is National Theater, a very important role is played by symbolic factors such as tradition or atmosphere. However, other motivations more typical of general performing arts audiences are also to be found among the National Theater visitors (e.g. importance of repertoire resonates with what described by Johnson \& Garbarino, 2001).

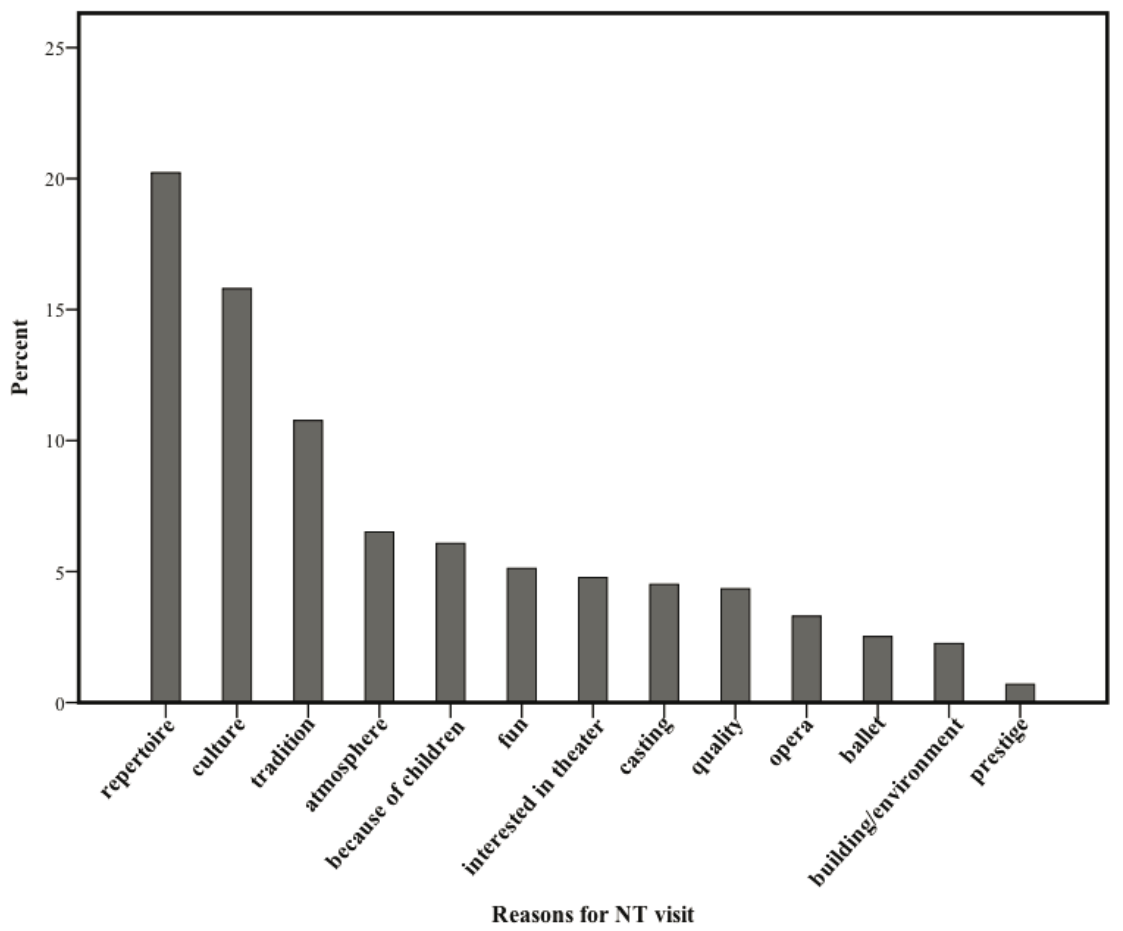

Fig. 3 - Motivation for NT performance attendance. Source: Authors

As already noted, we have found that the motivation for the theater visit plays a significant role in the frequency of theater attendance (Chi-Square $=116.655$, significant at $1 \%$ significance level). What are the most significant motivations can be seen at Tab. 5 (for clarity, some categories resulting as non-significant have been omitted). 
Tab. 5 - Motivation for attendance/frequency of performance attendance. Source: Authors

\begin{tabular}{|c|c|c|c|c|c|c|c|c|c|c|}
\hline & 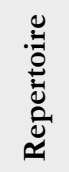 & 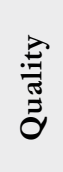 & 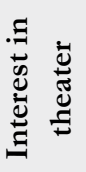 & & 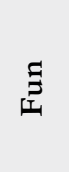 & ڤัँّ & 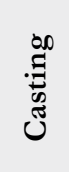 & 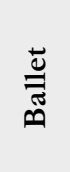 & 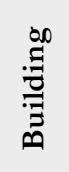 & 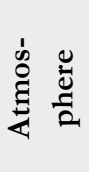 \\
\hline $\begin{array}{l}\text { More than once } \\
\text { a year }\end{array}$ & -0.8 & 0.5 & 3.6 & 2.4 & -3.8 & -1.9 & 0.7 & -2.6 & -2.3 & -1.8 \\
\hline Once a year & 0.9 & 0.2 & -3.0 & -1.9 & 2.3 & 2.2 & -0.3 & 2.7 & 2.4 & 1.9 \\
\hline First visit & -0.2 & -1.5 & -1.6 & -1.5 & 3.8 & -0.5 & -0.8 & -0.2 & -0.1 & 0 \\
\hline
\end{tabular}

Interestingly, the traditional motivations that are usually found among performing arts consumers, such as repertoire, quality or casting, do not play a significant role in the frequency of attendance among frequent National Theater goers. What does seem to be crucial is the interest in theater as such. Those of the respondents who are interested in theater generally, are also among the most frequent visitors. For these visitors, also, what is not so important is the building that evokes the historical background and national importance. This, on the other hand, is an important motivational factor for those who do come regularly, but not frequently. Second of all, it is the tradition that brings the most frequent visitors. Tradition here refers to the personal tradition of theater going, as well as the traditional take on performing arts in the National Theater. On the contrary, those visitors seeking fun are more among those who visit the National Theater for the first time or less frequently. Interestingly, opera or ballet goers are also among regular, yet not too frequent attenders.

Such results give some indications for the marketing of National Theater. As opposed to what may be an intuitive conclusion that consumers attend the theater for repertoire, quality, casting, but also the atmosphere of the National Theater, the frequent visitors attend rather for their interest in theater and for tradition.

Finally, visitors' motivations differ significantly when attending different kinds of performances. As can be noted in Tab. 6, consumers attending a play are less concerned by quality, but more motivated by casting. This is understandable, as drama actors and their qualities are more known to the general public than opera singers or ballet dancers. Opera goers, on the other hand, are more motivated by the quality of the performance as such. Again, this is understandable, as occasions to visit quality opera are scarce in Prague. Finally, those attending a ballet do so for their interest in theater, but also for their children. This is an interesting finding, as it shows that ballet is perceived as the kind of performing art that is most fairy-tale-like and thus adapt for children.

Tab. 6 - Type of visited performance/motivation. Source: Authors

\begin{tabular}{|l|c|c|c|c|c|}
\hline & Repertoire & Quality & $\begin{array}{c}\text { Interest in } \\
\text { theater }\end{array}$ & Casting & Children \\
\hline Play & 1.7 & -4.2 & -3.9 & 3.7 & -1.5 \\
\hline Ballet & -0.7 & -3.6 & 5.7 & -3.0 & 2.5 \\
\hline Opera & -1.2 & 8.7 & -1.8 & -0.9 & -1.0 \\
\hline
\end{tabular}




\section{DISCUSSION AND CONCLUSIONS}

In this paper we have discussed the application of marketing tools in the area of classical performing arts. It has been noted elsewhere (e.g. Fraser, 2004) that these tend to be limited to mostly communication-related instruments that are tactical in nature. This may be, among others, due to the belief that classical performing art, as high cultural production, should be ideologically neutral (Hirschman, 1983; Harrison, 2009), and thus not depend on the individuation of consumers' needs. However, there is an increasing discussion about the disappearing distinction between high and low culture, as both tend to become part of the market. At the same time, as the public funding slowly dries out, classical performing arts institutions are increasingly pressured to become economically sustainable.

As a consequence, there is no question that marketing tools that go beyond "selling what's on stock" should be used. The sole utilization of communication tools resonates too strongly with the obsolete "production-oriented" marketing that does not allow to create an offer that appeals to consumers. And within the increasingly competitive environment that starts to be evident also in the classical performing arts area, the ability to do so will decide the winners. In order to create a targeted offer, marketers should not concentrate solely on the "artistic production" (such as the repertoire, physical surroundings, etc.), but also, if not primarily, on the "artistic consumption". Then, instruments of targeted marketing such as segmentation can help institutions working in this sphere to create a better targeted offer, as well as communicate it more effectively.

The traditional way to describe classical performing arts audiences reported in literature, however, is often based on social class or its components (e.g. Baumol and Bowen, 1966; DiMaggio and Useen, 1978; Kotler \& Scheff, 1997; Lewis \& Seaman, 2004; Borgonovi, 2004; Masters et al., 2011). We argue that this view is too grounded in a particular (mostly Western) context and does not apply across different settings. In particular, this category is problematic in our case of the Czech National Theater, where consumers' income does not play a role in the frequency of their attendance. This may be due to the historical evolution of the particular context of Czech Republic, where historically theater has played a rather different role than in the settings other studies have been carried out in. The National Theater (and theater as such) has played a significant role in the formation of the Czech national identity, especially during the national awakening period, in which it formed a part of popular culture and a means to communicate and create national identity. Later, during the communist period, it was marketed as people's entertainment, and as such was again not a part of the high culture reserved to the higher classes. Such evolution is at odds with the development in other contexts. This difference is then reflected in our data, where social class (especially income levels) does not play a role in consumers' frequency of attendance of classical performances.

We can thus conclude that in the international literature regarding classical performing arts audiences' segmentation, especially where treating social class as a predictor for attendance, a crucial element has been omitted: the consideration of context.

What we propose, then, is rather a division of consumers based on their particular motivations to attend a performance. As our results show, such variable may yield better results and may also be more context sensitive, as it can be easily adapted. This can be done through a process similar to the one described in this paper. The marketer should first consider what are the benefits that consumer draws from the offered artistic experience. Knowing what benefits are sought by 
different groups of consumers, it is possible to target particular segments with a specific offer. Knowing, for instance, that frequent attenders are generally interested in theater, while regular (but not frequent) visitors prefer fun, can offer interesting material for specifically targeted offer. Similarly, this kind of information can also provide valuable insight for a targeted communication campaign.

\section{Acknowledgments:}

This article is a result of the research project "Efective methods for the increase of national and European competitiveness of small and medium enterprises in the field of culture" registered with the Ministry of Culture (program NAKI) under the number MK DF11P01OVV024.

\section{References}

1. Agresti, A. (2002). Categorical Data Analysis. New York: Wiley. http://dx.doi. org/10.1002/0471249688

2. Andreasen, A. R. (1987). Expanding the Audience for the Performing Arts. Washington, DC: National Endowment for the Arts, Research Div.

3. Andreasen, A. R. (2012). Rethinking the Relationship Between Social/Nonprofit Marketing and Commercial Marketing. Journal of Public Policy \& Marketing, 31 (1), 36-41. http:// dx.doi.org/10.1509/jppm.09.035

4. Andreasen, A. R. \& Belk, R. (1980). Predictors of Attendance at the Performing Arts. Journal of Consumer Research, 7 (2), 112-120. http://dx.doi.org/10.1086/208800

5. Arnould, E. J., \& Thompson, C. J. (2005). Consumer Culture Theory (CCT): Twenty Years of Research. Journal of Consumer Research, 31 (4), 868-882. http://dx.doi.org/10.1086/426626

6. Ateca-Amestoy, V. (2008). Determining heterogeneous behavior for theater attendance. Journal of Cultural Economics, 32 (2), 127-151. http://dx.doi.org/10.1007/s10824-008-9065-z

7. Borgonovi, F. (2004). Performing arts attendance: an economic approach. Applied Economics, 36 (17), 1871-1885. http://dx.doi.org/10.1080/0003684042000264010

8. Baumol, W. \& Bowen, W. (1980). Performing arts - The economic dilemma. Cambridge: MIT Press.

9. Botti, S. (2000). What Role for Marketing in the Arts? An Analysis of Arts Consumption and Artistic Value. International Journal of Arts Management, 2 (3), 14-27.

10. Bourdieu, P. (1984). Distinction: A Social Critique of the Judgement of Taste. London: Routledge \& Kegan and Paul.

11. Colbert, F.; Nantel, J.; Bilodeau, S. \& Rich, J.D. (2001). Marketing Culture and the Arts. Montreal: HEC, Chair in Arts Management.

12. DiMaggio, P. \& Useem, M. (1978). Social class and arts consumption: The origins and consequences of class differences in exposure to the arts in America. Theory and Society, 5 (2), 141-161. http://dx.doi.org/10.1007/BF01702159

13. Favaro, D., \& Frateschi, C. (2007). A discrete choice model of consumption of cultural goods: the case of music. Journal of Cultural Economics, 31 (3), 205-234. http://dx.doi. org/10.1007/s10824-007-9043-x

14. Featherstone, M. (1991). Consumer Culture and Postmodernism. London: Sage Publications. 
15. Fraser, I. (2004). The Marketing of Theater. In. Carrigan, F., Fraser, P. \& Ozbilgin, M. (Eds.) Arts Marketing (42-67). Burlington: Elsevier Butterworth-Heinemann.

16. Hirschman, E. C. (1983). Aesthetics, Ideologies and the Limits of the Marketing Concept. Journal of Marketing, 47 (3), 45-55. http://dx.doi.org/10.2307/1251196

17. Holbrook, Morris B. (1995). Consumer research: Introspective essays on the study of consumption. Thousand Oaks: Sage Publications.

18. Holbrook, M. B. \& Schindler, R. M. (1994). Age, Sex, and Attitude toward the past as Predictors of Consumers' Aesthetic Tastes for Cultural Products. Journal of Marketing Research, 31 (3), 412-422. http://dx.doi.org/10.2307/3152228

19. Hollander, S. C. (1984). Sumptuary Legislation: Demarketing by Edict. Journal of Macromarketing, 4 (1), 4-16. http://dx.doi.org/10.1177/027614678400400102

20. Becker, H. S. (1978). Arts and Crafts. American Journal of Sociology, 83 (4), 862-889. http:// dx.doi.org/10.1086/226635

21. Bernstein, J.S. (2007). Arts Marketing Insights: The Dynamics of Building and Retaining Performing Arts Audiences. San Francisco: John Wiley \& Sons.

22. Falk, M. \& Falk, R. (2011). An Ordered Probit Model of Live Performance Attendance for 24 EU Countries. Paper presented at Birmingham business school May 19, 2011.

23. Huntington, C. S. (2007). Reevaluating Segmentation Practices and Public Policy in Classical Performing Arts Marketing: A Macro Approach. The Journal of Arts Management, Law, and Society, 37 (2). http://dx.doi.org/10.3200/JAML.37.2.127-142

24. Johnson, M. S. \& Garbarino, E. (2001). Customers of performing arts organisations: are subscribers different from nonsubscribers? International Journal of Nonprofit and Voluntary Sector Marketing, 6 (1), 61-77. http://dx.doi.org/10.1002/nvsm.134

25. Kotler, P. \& Armstrong, G. (2007). Principles of Marketing. Upper Saddle River, NJ: Prentice Hall.

26. Kotler P. \& Levy, S. (1969). Broadening the Concept of Marketing. Journal of Marketing, 33 (1), 10-15. http://dx.doi.org/10.2307/1248740

27. Kotler, P. \& Scheff, J. (1997). Standing Room Only: Strategies for Marketing the Performing Arts. Boston, MA: Harvard Business Review Press.

28. Lewis, G. \& Seaman, B.A. (2004). Sexual Orientation and Demand for the Arts. Social Science Quarterly, 85 (3), 523-538. http://dx.doi.org/10.1111/j.0038-4941.2004.00231.x

29. Masters, T., Russell, R., \& Brooks, R. (2011). The demand for creative arts in regional Victoria, Australia. Applied Economics, 43 (5), 619-629. http://dx.doi.org/10.1080/000368408 02584976

30. Ngobo, P. V. (2005). Drivers of upward and downward migration: An empirical investigation among theatregoers. International Journal of Research in Marketing, 22 (2), 183-201. http:// dx.doi.org/10.1016/j.ijresmar.2004.07.002

31. Pallin, G. (2003). Stage Management: The Essential Handbook. London: Nick Hern Books Ltd.

32. Seaman, B.A. (2006). Empirical Studies of Demand for the Performing Arts. In. D.

Throsby, D. \& Ginsburgh, V. (Eds.) Handbook of the Economics of Art and Culture (415-472), Amsterdam: North-Holland (Elsevier). http://dx.doi.org/10.1016/S1574-0676(06)01014-3 
33. Solomon, M. R., Bamossy, G., Askegaard, S. \& Hogg, M. K. (2010). Consumer Behaviour: A European Perspective. London: Prentice Hall.

34. Venkatesh, A., \& Meamber, L. A. (2006). Arts and aesthetics: Marketing and cultural production. Marketing Theory, 6 (11), 11-39. http://dx.doi.org/10.1177/1470593106061261

35. Willis, K.G., Snowball, J.D., Wymer, C \& Grisolía, J. (2012). A count data travel cost model of theatre demand using aggregate theatre booking data. Journal of Cultural Economics, 36 (2), 91-112. http://dx.doi.org/10.1007/s10824-011-9157-z

\section{Contact information:}

Ing. Zuzana Chytková, Ph.D.,

Ing. Jitka Cerná, Ph.D.,

Ing. Miroslav Karliček, Ph.D.

Department of Marketing, University of Economics, Prague

Nam. W. Churchilla 4

13067 Praba 3, Czech Republic

email: zuzana.chytkova@vse.cz; cernaj@vse.cz;miroslav.karlicek@vse.cz.

JEL Classification: M30, M31, M39 